\title{
BM] Global Health Fighting TB stigma: we need to apply lessons learnt from HIV activism
}

\author{
Amrita Daftary, ${ }^{1,2}$ Mike Frick, ${ }^{3}$ Nandita Venkatesan, ${ }^{4}$ Madhukar Pai ${ }^{1,5}$
}

To cite: Daftary A, Frick M, Venkatesan $\mathrm{N}$, et al. Fighting TB stigma: we need to apply lessons learnt from HIV activism. BMJ Glob Health 2017;2:e000515. doi:10.1136/ bmigh-2017-000515

\section{Handling editor Seye Abimbola}

Received 5 August 2017 Revised 28 September 2017 Accepted 29 September 2017

\section{(a) CrossMark}

${ }^{1}$ Department of Epidemiology, Biostatistics and Occupational Health, and McGill International TB Centre, McGill University, Montreal, Quebec, Canada ${ }^{2}$ Centre for the Aids Programme of Research in South Africa (CAPRISA), University of KwaZulu-Natal, Durban, KwaZulu-Natal, South Africa ${ }^{3}$ Treatment Action Group, New York City, New York, USA

${ }^{4}$ Survivors Against TB, Mumbai, Maharashtra, India

${ }^{5}$ Manipal McGill Centre for Infectious Diseases, Manipal University, Manipal, Karnataka, India

Correspondence to

Amrita Daftary;

amrita.daftary@mcgill.ca
In $2015,10.4$ million people were diagnosed with tuberculosis $(\mathrm{TB})^{1}$ and 2.1 million people tested positive for HIV. ${ }^{2}$ Over two-thirds of new TB and HIV infections are in lower income and middle-income countries in sub-Saharan Africa and Asia. Together, TB and HIV cause over 2.5 million deaths each year, ${ }^{12}$ and immeasurable social calamities. Key among these is widespread stigmatisation incited by their deep-set association with poverty, social marginalisation, risk of transmission and death, and perpetuated to varying degrees by subversive policies and practices. ${ }^{3}{ }^{4}$ The stigma is doubly worse for the 1.2 million people world over who live with both infections. ${ }^{15}$

Since its outset in the 1980s, people with HIV and health activists have galvanised HIV stigma into a force for social change. ${ }^{6}$ They have willed action against prejudicial practices with tangible transformative effects at the individual, policy and political level. ${ }^{7}$ HIV-related discrimination has been confronted with empowerment. Policies such as those for HIV testing, treatment, counselling, medication access and employment of persons with HIV seek to affirm and uphold the rights of those affected by HIV. ${ }^{8}$ When the fulfilment of human rights has fallen short in practice, HIV activists have used rights-based approaches to overcome stigma and discrimination, and organise for change.

The TB community has always recognised the stigma that surrounds the disease but has done far less to confront it. ${ }^{910}$ The risk and fear of transmission of the airborne infection are often raised in defence of policies and practices that prioritise the well-being of the collective public over that of individual patients. ${ }^{11}$ Persons with TB or presumed to have $\mathrm{TB}$ continue to be subjected to stigmatising language (eg, 'TB suspects', 'defaulters'), mandatory screening, testing and disease notification systems that lack privacy, contact investigations that label index patients, airborne respiratory isolation that prolongs their social isolation, directly

\section{Summary box}

- The global tuberculosis (TB) and HIV epidemics are worsened by stigmatisation that is incited by their association with poverty, social marginalisation, risk of transmission and death, and may be perpetuated by subversive policies and practices.

- The HIV community has successfully rallied forces to challenge the stigmatisation of people with HIV, through collective, grassroots human rights movements that have led to tangible shifts in policy. The TB community has not adequately contested programmatic norms that reinforce TB stigma.

- The TB community not adequately contested age-old programmatic norms that reinforce the stigmatisation of people with or affected by TB.

- Raising awareness about TB stigma is insufficient to mitigate stigma. The TB community needs consciousness raising, a form of activism where people with and affected by TB come together to share their experiences, identify common struggles and begin collectively organising to change harmful practices.

- TB science can be used to affirm the rights and dignity of people with TB. Common TB policies and practices can be modified to reduce TB stigma, informed by lessons from HIV activism.

observed treatment (DOT) that impedes individual autonomy, and in rare but relevant cases, legal detention and even incarceration of those who refuse or stop treatment. ${ }^{711} 12$ As these practices continue to be applied in biomedical, public health-oriented ways, they fuel the social exclusion of people with TB, and reify assumed conflicts between public health and patient rights. ${ }^{713}$

People with multidrug-resistant or extensively drug-resistant TB (M/XDR-TB), the most clinically severe forms of $\mathrm{TB}$, are often the most judged and stigmatised. ${ }^{14}$ As non-adherence to $\mathrm{TB}$ treatment is considered to be one cause of developing drug resistance, patients with $\mathrm{M} / \mathrm{XDR}-\mathrm{TB}$ are routinely reprimanded for having been 'non compliant' to previous treatments with neglect to the sociomedical environment in 
Table 1 Recommendations to modify practices that may compound stigmatisation of patients with tuberculosis (TB)

\section{TB policy or}

practice Strategies to mitigate stigma

\begin{tabular}{ll}
\hline TB screening & Inform and counsel patients about TB and/or differential diagnoses pre and post screening and testing \\
and testing & Protect patient confidentiality (eg, share test results in private) \\
& Advise patients of their right to access treatment
\end{tabular}

TB notification - Protect confidentiality of TB test results and patient anonymity (eg, use unique patient IDs, or draw on local HIV reporting methods)

- Institute safeguards to ensure that TB test status does not affect a person's employment status, immigration status or qualification for other government benefits or services (eg, implement firewall policies between public health services and other state functions such as immigration and border control)

$\begin{array}{ll}\text { Contact tracing } & \text { Integrate TB-related health literacy and counselling into contact investigations (eg, family counselling, } \\ & \text { support patients in ways to disclose their illness) } \\ & \text { Protect patient confidentiality (eg, avoid naming or labelling the index patient wherever possible) } \\ \text { Provide preventive therapy where warranted (ie, ensure that a TB diagnosis is followed by the option to } \\ \text { initiate therapy under free and informed consent) } \\ \text { Infection } & \text { Inform and counsel patients about TB transmission risks and measures to reduce these risks } \\ \text { control } & \text { Normalise face mask use and emphasise its capacity to protect patients in addition to contacts } \\ \text { measures } & \text { Test sputum routinely to identify conversion/non-infectivity, to enable early discharge from isolation, and } \\ & \text { use rapid tests such as Xpert MTB/RIF to facilitate this }\end{array}$

$\begin{array}{ll}\text { TB treatment } & \text { Inform and counsel patients about TB treatment, including duration, potential side effects, expected } \\ \text { initiation } & \text { benefits, availability of free treatment and the importance of adherence } \\ & \text { Promote equitable access to newer, safer, shorter treatment regimens } \\ \text { - } & \text { Engage patients in decisions regarding auxiliary therapy, where possible (eg, management of adverse } \\ & \text { Refer patients to services and resources to facilitate adequate support for adherence, including referral to } \\ \text { champion patients and TB survivors } \\ \text { - Advise patients of their right to access treatment as opposed to just their mandate to initiate and adhere to } \\ \text { therapy } \\ \text { - Establish systems that respect patient decisions to access TB services from their preferred provider and } \\ \text { maintain continuity of care (eg, public-private health partnerships, integration of TB and HIV services) } \\ \text { TB treatment } \\ \text { monitoring } & \text { Build TB treatment literacy to support self-administration } \\ & \text { Implement adherence promotion strategies that are feasible and acceptable to patients (eg, phone } \\ & \text { reminders, smart pill boxes, peer networks) } \\ & \text { Promote mechanisms to protect patients' employment and enable access to social security during TB } \\ & \text { treatment } \\ & \text { Facilitate safe reintegration of patients into social and work settings to foster social well-being and } \\ & \text { financial independence (eg, by sensitising employers and families to TB) } \\ & \text { Assess palliative care needs and resources for patients who may be incurable, and their caregivers }\end{array}$

$\begin{array}{ll}\text { TB research } & \text { Involve research participants and other community members and stakeholders in the research } \\ \text { activities } & \text { development and dissemination process (eg, following the recommendations of the Good Participatory } \\ & \text { Practices for TB Drug Trials) } \\ & \text { Create a community advisory group to inform the research process and ensure that research practices and } \\ & \text { procedures do not inadvertently result in stigmatisation of patients with TB } \\ \text { TB } & \text { Raise global consciousness by connecting TB-affected communities through media and other forms of } \\ \text { consciousness } & \text { public representation (eg, via stories and images of healthy TB survivors rather than those that reinforce } \\ \text { and awareness } & \text { negative stereotypes against groups most affected by TB) } \\ \text { raising } & \text { Disrupt the current narrative underlying practices that may be stigmatising (eg, reframe TB screening and } \\ \text { activities } & \text { contact tracing practices as empowering so that an index patient gains control of his/her illness and uses } \\ & \text { this knowledge to protect others) } \\ & \text { Use TB science to affirm rather than neglect the rights of patients with TB (eg, emphasise when a patient } \\ & \text { becomes non-infectious just as vigorously as his/her infectious state was emphasised) } \\ & \text { Sensitise employers to support employees with TB and promote employment of TB survivors } \\ & \text { Build spaces for consciousness raising by bringing together people affected by TB to share their } \\ & \text { experiences, identify common challenges, and organise to change practices that reify stigma or impede } \\ & \text { patient-centred care (eg, through peer networks and advocacy forums) } \\ & \text { Routinely invite TB survivors to speak at (even open) TB conferences and meetings, to acknowledge their } \\ & \text { suffering and to give them a voice in the mainstream TB community }\end{array}$


which adherence transpires-one that is fraught with low-quality health systems, patient-provider mistrust, primary drug resistance, and poor access to diagnostic tools, new drugs, treatment literacy, social protections and infection control. ${ }^{15}$ Similarly, in many low-incidence countries, specific population groups such as migrants and refugees are portrayed as a public health threat and blamed for being carriers of TB. ${ }^{16}$ We are in need of a counternarrative to debunk timeworn arguments that continue to hold individual patients culpable for population-level failures and outcomes.

In recent years, key actors in the TB community, such as the Stop TB Partnership, Treatment Action Group, TB PROOF, Global Coalition of Tuberculosis Activists and KNCV Tuberculosis Foundation, to name just a few, are creating meaningful change in the praxis of TB care with potential effects on stigma reduction. ${ }^{11} 131718$ Terms that reinforce negative stereotyping of people with $\mathrm{TB}$ are being extricated from clinicians' and researchers' vocabularies. ${ }^{11}$ The hardline DOT approach is gradually ceding to patient-centred approaches that emphasise community engagement, patient counselling and structural aid in adherence promotion, even a murmur of palliative care for those with incurable disease. ${ }^{15}$ Governments and industry are being held accountable for implementing new technologies to ensure equitable access to the fruits of scientific advancement. ${ }^{13}$ Global health ambassadors including $\mathrm{TB}$ survivors are raising awareness about $\mathrm{TB}$ on a societal level through messages that affirm the dignity of people with TB rather than amplify the fear of TB. ${ }^{11}$

But this gradual advocacy movement of awareness raising, while necessary, is insufficient to tackle the structural drivers of stigma. The TB community needs consciousness raising, a form of activism that connects disparate experiences of discrimination and disenfranchisement, and the systems and structures that abet them, across time and space. ${ }^{19}$ Consciousness raising can take place when people with and affected by TB come together to share their experiences, identify common struggles and, based on this foundation, begin collectively organising to change practices that are stigmatising and potentially harmful. The resulting solidarity, characteristics of which we see in communities affected by HIV across the globe, and who are linked despite differences in race, sex and economy, can lay the foundation for more lasting social change. Replacing images of radiographs or mycobacteria, for example, with the well faces of those who have braved TB may help connect communities and humanise TB. Implementing a comprehensive framework for TB treatment literacy may allow counselling efforts to mature from piecemeal to universal practice. Framing contact investigations as a way for patients with $\mathrm{TB}$ to protect, rather than disrupt, their position in the household may avoid alienating index cases. TB science and the methods by which it is implemented can help to accelerate this transformation to better affirm the rights and dignity of people with TB. Knowledge of TB transmission most often used to isolate-and at times incriminate-patients can be harnessed to emphasise the stage at which patients become non-infectious.

Destigmatising TB is well aligned with 'zero suffering', a prominent goal of the WHO's new End TB Strategy distinct from the goal of zero infections and zero deaths. ${ }^{20}$ One step towards alleviating patient suffering is to revisit policies and practices that fuel TB stigma and raise global consciousness for an inclusive and non-stigmatising approach to TB care (see table 1 for our recommendations). It is time we combated stagnant policies and complacency that diminish the social value of people with $\mathrm{TB}$, and indeed feed into derogation of the epidemic itself in the hierarchy of global health challenges. ${ }^{21}$ As actors in the TB community continue working bottom-up to create micro forces of change, the healthcare system, scientific community, industry and donor agencies must sign on to stimulate a tangible shift through collective action and collective voice-one that is loud enough for 10 million voices to be heard.

Contributors $A D$ and MF wrote the first draft of this commentary. AD, MF and MP reviewed and approved the final version.

Competing interests MP serves as a consultant to the Bill \& Melinda Gates Foundation (BMGF). BMGF had no involvement in this publication.

Provenance and peer review Not commissioned; externally peer reviewed. Data sharing statement № additional data are available.

Open Access This is an Open Access article distributed in accordance with the Creative Commons Attribution Non Commercial (CC BY-NC 4.0) license, which permits others to distribute, remix, adapt, build upon this work non-commercially, and license their derivative works on different terms, provided the original work is properly cited and the use is non-commercial. See: http://creativecommons.org/ licenses/by-nc/4.0/

(c) Article author(s) (or their employer(s) unless otherwise stated in the text of the article) 2017. All rights reserved. No commercial use is permitted unless otherwise expressly granted.

\section{REFERENCES}

1. WHO. Global TB Report. Geneva: World Health Organization, 2016

2. UNAIDS. Fact sheet: latest statistics on the status of the AIDS epidemic. Geneva: Joint United Nations Programme on HIV/AIDS, 2016.

3. Link BG, Phelan JC. Stigma and its public health implications. Lancet 2006;367:528-9.

4. Parker R, Aggleton P. HIV and AIDS-related stigma and discrimination: a conceptual framework and implications for action. Soc Sci Med 2003;57:13-24.

5. Daftary A. HIV and tuberculosis: the construction and management of double stigma. Soc Sci Med 2012;74:1512-9.

6. Stangl AL, Lloyd JK, Brady LM, et al. A systematic review of interventions to reduce HIV-related stigma and discrimination from 2002 to 2013: how far have we come? J Int AIDS Soc 2013;16(3 Suppl 2):18734.

7. Daftary A, Calzavara L, Padayatchi N. The contrasting cultures of HIV and tuberculosis care. AIDS 2015;29:1-4.

8. Gruskin S, Tarantola D. Universal Access to HIV prevention, treatment and care: assessing the inclusion of human rights in international and national strategic plans. AIDS 2008;22(Suppl 2):S113-21.

9. Courtwright A, Turner AN. Tuberculosis and stigmatization: pathways and interventions. Public Health Rep 2010;125(Suppl 4):34-42.

10. Sommerland N, Wouters E, Mitchell EMH, et al. Evidence-based interventions to reduce tuberculosis stigma: a systematic review. Int J Tuberc Lung Dis 2017;21:81-6.

11. Frick $M$, von Delft $D$, Kumar $B$. End stigmatizing language in tuberculosis research and practice. BMJ 2015;350:h1479. 
12. Maleche A, Were N. Petition 329: a Legal Challenge to the Involuntary Confinement of TB Patients in Kenyan Prisons. Health Hum Rights 2016;18:103-8.

13. Frick M, Henry I, Lessem E. Falling Short of the Rights to Health and Scientific Progress: Inadequate TB Drug Research and Access. Health Hum Rights 2016;18:9-24.

14. Daftary A, Padayatchi N, O'Donnell M. Preferential adherence to antiretroviral therapy over tuberculosis treatment: a qualitative study of drug-resistant TB/HIV co-infected patients in South Africa. Glob Public Health 2014;9:1107-16.

15. O'Donnell MR, Daftary A, Frick M, et al. Re-inventing adherence: toward a patient-centered model of care for drug-resistant tuberculosis and HIV. Int J Tuberc Lung Dis 2016;20:430-4.

16. Craig GM, Daftary A, Engel N, et al. Tuberculosis stigma as a social determinant of health: a systematic mapping review of research in low incidence countries. Int J Infect Dis 2017;56:90-100.
17. WHO. Every Word Counts: Suggested Language Usage for Tuberculosis Communications. Geneva: Stop TB Partnership, World Health Organization, 2015.

18 Mitchell EMH, Daftary A. TB stigma: clearing the fog. Int J Tuberc Lung Dis 2017;21:1.

19 Sharpe L, Ginsburg G, Gordon G, et al. Trying to make the personal political: feminism and consciousness-raising - a reprint of consciousness raising guidelines (1975). Chicago: Women's Action Alliance, Half Letter Press, 2017.

20 WHO. The End TB Strategy. Geneva: World Health Organization, 2015.

21 Lewis S. A Call to Action for TB Plenary. 47th Union World Conference on Lung Health. Liverpool, 2016. 